University of Nebraska - Lincoln DigitalCommons@University of Nebraska - Lincoln

Avian Cognition Papers

Center for Avian Cognition

1983

\title{
Optimal Foraging Theory and the Psychology of Learning
}

Alan Kamil

Follow this and additional works at: https: / digitalcommons.unl.edu/biosciaviancog

Part of the Animal Studies Commons, Behavior and Ethology Commons, Cognition and Perception Commons, Forest Sciences Commons, Ornithology Commons, and the Other Psychology Commons 


\title{
Optimal Foraging Theory and the Psychology of Learning
}

\author{
Alan C. Kamil \\ Departments of Psychology and Zoology \\ University of Massachusetts \\ Amherst, Massachusetts 01003
}

\begin{abstract}
Synopsis
The development of optimization theory has made important contributions to the study of animal behavior. But the optimization approach needs to be integrated with other methods of ethology and psychology. For example, the ability to learn is an important component of efficient foraging behavior in many species, and the psychology of animal learning could contribute substantially to testing and extending the predictions of optimal foraging theory.
\end{abstract}

\section{Introduction}

When the animal behavior literature of the 1960 s is compared with the literature of today, it is apparent that a revolution has taken place. Many of the phenomena of behavioral ecology and sociobiology that are taken for granted today, that are presented in undergraduate textbooks (e.g., Krebs and Davies, 1981), would have seemed implausible just 15 to 20 years ago. This radical change in how we regard animal

Published in American Zoologist, 23 (1983), pp 291-302.

doi 10.1093/icb/23.2.291

Copyright (c) 1983 by the American Society of Zoologists

From the Symposium on Optimization of Behavior presented at the Annual Meeting of the American Society of Zoologists, 27-30 December 1981, at Dallas, Texas. 
behavior is due in part to the development of optimization theory. Optimization theory can be regarded as a logical extension of the adaptive approach to the study of animal behavior long espoused by ethologists (e.g., Tinbergen, 1963), but the development of optimization models has had enormous impact. By deriving solutions to specific behavioral problems, optimization models have generated testable predictions which have stimulated research, suggesting novel ways in which the fine details of the behavior of an animal could affect biological success.

By focusing attention upon the behavior of individual animals, optimization theory also contributed to an important methodological development, increased data collection with identifiable individual animals over time, under natural conditions. Although this type of data collection was becoming more common before the advent of optimization theory (e.g., Tinbergen, 1960: van Lawick-Goodall, 1968), it received additional impetus from optimization theory, which focusses on the behavior of individuals. The importance of this methodological development should not be underestimated. Many of the most interesting phenomena of behavioral ecology and sociobiology could only become apparent after such data were collected. Examples include adjustments in territoriality and territory size in response to changes in nectar availability by sunbirds (Gill and Wolf, 1975), social competition within groups of communally nesting birds (Vehrencamp, 1977), the apparent avoidance of toxin-laden leaves by howler monkeys (Glander, 1981) and adjustments in diet in response to changes in prey density by redshanks (Goss-Custard, 1981).

In spite of these contributions, optimization theory has been subjected to substantial criticism (e.g., Gould and Lewontin, 1979; see also Maynard-Smith, 1978). Much of this criticism has centered around three issues. (1) Tests of optimization theory are not legitimate tests of the hypothesis that behavior is adapted. (2) Many optimization models, particularly optimal foraging models, are too simple, in light of the complexity of the challenges an animal faces in nature (Zach and Smith, 1981). (3) The fit between the predictions of the models and the data is often only qualitative, and the apparent quantitative precision of the models is misleading.

A problem related to these criticisms is that although optimization models are based on the assumption that animals are perfectly adapted, there are many reasons to doubt that optimally functional 
behavior will be found very often. For one thing, optimality would depend upon the rate of evolutionary change being rapid enough to track environmental change, and some lag must occur frequently. There may be costs or constraints which make optimal behavior unlikely or impossible (Orians, 1981). Many situations may be sufficiently multidimensional to rule out any single optimal solution. How can we resolve the apparent paradox of the practical utility of optimization theory with the substantial criticisms it has received and with the probable inaccuracy of its basic premise?

The answer to this question is simple, and involves placing emphasis on the term practical utility. Our goal as biological scientists is to understand the animals we study. Ethologists and behavioral ecologists need to remember that the subject under investigation is behavior, not adaptation, optimization or even evolution. Concepts such as optimization are theoretical constructs that we use to help us understand and predict behavior, but are not themselves the objects of study. In this context, the question is whether a particular concept has heuristic value, and for optimization theory the answer is clearly yes. As indicated above, elsewhere in this symposium, and throughout the animal behavior literature of today, many experiments in both laboratory and field have demonstrated the practical value of optimization theory.

From this point of view, many of the criticisms of optimization theory seem unimportant. The argument that optimization theory does not provide a legitimate test of the adaptedness of behavior is correct, but largely irrelevant. There are other, more appropriate methods available to test the adaptedness hypothesis (e.g.. Curio, 1973). The qualitative fit between theory and data, and the relative simplicity of optimization models present challenges for future theoretical and empirical work. And the reasons why nonoptimality often may be expected are reminders that optimization is a useful concept, but not necessarily an inherent characteristic of behavior.

We are now at the beginning of the second stage of the development of optimization theory. The first stage has been relatively short and quite exciting. During this initial stage theoretical advances often have proceeded more rapidly than empirical developments, and attention frequently has been focused narrowly on optimization theory as an end in and of itself. In a way, it reminds me of what happened in my laboratory when we got our first computer for the on-line control of experiments. At first we tried to do everything imaginable with it. 
There were even experiments performed which, in retrospect, seem to have been intended to explore the limits of the computer rather than the behavior of the blue jays we were studying. But that first stage passed. We came to realize that some things could still best be done with the older tools-relays or stop watches. The computer then assumed its rightful place as one of the tools we use for accomplishing our goal. Similarly, we must recognize that optimization theory cannot do it all. The complete understanding of behavior will require the use of optimization theory, but only as one of the tools we use. During the second stage of the development of optimization theory, the information gained because of optimization theory must be consolidated and integrated with other aspects of animal behavior.

One of the functions of scientific theories which optimization theory has served successfully is to direct our observations to particularly enlightening cases. Situations such as the depleting food patch or the group of animals of varying kinship already have repaid our efforts handsomely. However, the situations highlighted by optimization theory need to be examined more closely and comprehensively. There has been an occasional tendency to conduct research with a view towards testing optimization theory predictions rather narrowly, and this has led to limited data collection. This may lie at the heart of the criticisms Heinrich (1983) has levelled at some optimization research. In other instances, systematic departures from randomness have been labelled optimal very quickly, sometimes even in the absence of an\ particular model, ignoring the definition of the word optimal and possibly curtailing further investigation. These problems ma) point out the potential costs of any device which directs our attention in a particular direction. When looking very hard for one phenomenon, others may be overlooked easily.

Although it may be difficult, we must guard against tunnel vision. When the behavior of an animal does fit the predictions of optimization theory, the case is not closed. Many questions remain. We still need to determine how this behavior comes about, in terms of its physiology and ontogeny, for instance. And when behavior does not match our predictions very well, similar problems still remain; reworking our models is not the sole task confronting us when the models are in error.

Optimization theory overlaps substantially with ethology and comparative psychology in several areas. One of the most important of 
these is the effects of individual experience on behavior. Many optimization models imply that previous experience plays an essential role in the behaviors that these models predict. For example, kin recognition, judgements of reciprocal altruism, or estimates of expected rates of intake within a patch could all depend upon learning and memory. One particularly intriguing and promising area for integration lies between optimal foraging theory (OFT) and the psychological literature on animal learning (see Kamil and Yoerg, 1982, for a more detailed discussion of this issue).

\section{Psychology and Foraging Theory}

Most optimal foraging models imply that the animal possesses considerable information about the spatial and temporal distribution of its food. In many instances, this information could be acquired through previous experience. The resulting interest in learning on the part of ecologists is relatively recent. But experimental psychologists have a long-standing interest in animal learning. As a number of papers have pointed out, the approach of psychologists to animal learning has left much to be desired from a biological, evolutionary point of view (e.g., Hodos and Campbell, 1969; Seligman, 1970; Lockard, 1971; Kamil and Yoerg, 1982). In essence, the problem has been that psychologists have conceived of learning as composed of a few simple mechanisms which are quite general, both across species and across learning situations. In fact, psychologists made a very conscious attempt to study learning in biologically arbitrary situations. As Seligman has put it, "The very arbitrariness and unnaturalness of the experiment was assumed to guarantee generality, since the situation would be uncontaminated by past experience the organism might have had or by special biological propensities he might bring to it" (1970, p. 407).

Despite its shortcomings, the psychologist's approach to animal learning represents a coherent internally consistent system. It has had its successes, such as generating techniques which have proved useful in therapeutic and educational settings with humans. But this literature has, for the most part, been ignored by ecologists (but see Pulliam, 1981). There are at least two reasons for this. First of all, the ecological approach is very different from the psychological. Whereas the psychologist is primarily interested in mechanism and laboratory 
research, the ecologist is primarily interested in function and field work. Where the psychologist often thinks in terms of processes which are quite general across species, the ecologist often thinks in terms of each species as occupying a unique niche. These kinds of differences in basic approach make cross-disciplinary communication and understanding difficult. Secondly, the psychological literature on animal learning is a vast one, and is filled with special nomenclature (jargon to the outsider) which has been developed over the years, making this literature very difficult for a nonpsychologist to use.

Despite these problems, the psychology of animal learning can be a valuable resource for the ecologist interested in the potential roles of learning and memory in foraging behavior. In the course of their 80 or so years of research on animal learning, psychologists have successfully solved a number of methodological and conceptual issues of the analysis of animal learning. It would be a shame for ecologists to have to solve these same problems independently. It would be much more efficient and sensible for ecologists to take what they find useful from psychology.

The overlap between animal learning psychology and behavioral ecology can be seen most clearly in those instances in which workers from the two disciplines have carried out similar research. For example, there are strong similarities between the probability learning experiments of psychologists and the patch selection experiments of ecologists. In the typical probability learning experiment, a rat is placed in a maze and has two response alternatives on each trialit can either turn left or turn right. Each alternative is rewarded with food a certain percentage of the time, the two percentages usually summing to $1007 \mathrm{c}$ (e.g., 60-40, 75-25). The animal is allowed to choose left or right many times each day, for many days, until choice behavior reaches asymptote. Asymptote typically is almost exclusive choice of the response with the higher probability of reward. The psychological literature contains many experiments of this general type, and a great deal is known about probability learning. For example, animals usually begin training by selecting each alternative with approximately equal frequency and reach asymptote through a gradual, incremental change in behavior. The more similar the two choices are in their reward probabilities, the slower the learning (Uhl, 1963).

Several experiments in the optimal foraging literature are quite similar to these probability learning experiments (Smith and Sweatman, 
1974: Krebs el al., 1978). When an animal has two areas to hunt in, these areas can differ in prey density, and this difference can be unpredictable from day to day. The model proposed by Krebs et al. (1978) conceptualizes the behavior of the animal facing this situation as consisting of two discrete stages, sampling followed by exploitation. During the sampling phase, the animal should respond equally often to each alternative, gathering information about the current prey densities in the two areas. Once sufficient information has been gathered to allow an accurate decision, exploitation, exclusive choice of one of the alternatives, should ensue. The model then calculates the optimal switching point, which depends upon variables such as the degree of difference in densities between the two areas and the length of the foraging bout.

To test their model, Krebs et al. (1978) used a cage with two perches. The bird could hop on either perch, and these hops were rewarded with food on a probabilistic basis. During experimental sessions, the two perches differed in the probability of reward, and the better perch was randomly determined for each session. The independent variable was the degree of difference between the perches in reward probability. Qualitatively, the effect predicted by the model was obtained. Increasing the difference in payoff rates decreased the length of the sampling period. However, the measure of the duration of sampling was an indirect one, the number of hops necessary before the bird settled in on one of the perches, making 90\% or more of its remaining hops on that perch. Using this dependent variable as a measure of sampling, the quantitative fit to the model was very good.

However, this quantitative fit may be misleading, since it depends on the post hoc estimation of some parameters of the model as well as the use of the $90 \%$ criterion as a measure of sampling. If this experiment is viewed as a learning experiment rather than as a patch use experiment, the qualitative results are not surprising. As indicated above, taking longer to learn about the better of two alternatives when the differences between the alternatives is relatively small is a well known result in the psychological literature. A more critical issue concerns the shapes of the learning curves of the individual animals. The probability learning literature would lead us to expect a gradual change in behavior from equal choice of the alternatives to exclusive choice of one alternative, whereas the Krebs et al. (1978) model would lead us to expect a sudden, all-or-none change when the 
sampling period ended. Although Krebs el at. (1978) did not present the relevant data on the time course of choice for individual birds, at least some of the birds showed the gradual change we would expect from probability learning (Krebs, personal communication).

Despite these problems, the Krebs et al. (1978) paper is an important one. For ecologists, it demonstrates that the problem of sampling new or unpredictable environments can be investigated empirically. For psychologists, the paper demonstrates an alternative and potentially more productive view of the probability learning situation. For example, the two-armed bandit model implies that although the bird acquires information gradually during the sampling period, the change in behavior produced by this information is sudden. The Krebs et al. (1978) approach also suggests more concern should be directed at the problems that ensue when reward probabilities are subject to change, as do other ecological papers on patch use (Smith and Sweatman, 1974).

I would now like to discuss three concepts the animal learning literature offers the ecologist: The effects of previous experience on the speed of learning, the importance of acquisition and transfer experiments to understanding the variable' controlling the behavior of an animal in a learning situation, and the potential importance of schedules of reinforcement for foraging behavior. This should not be regarded as a complete list, only a set of useful examples.

\section{Experience and the speed of learning}

Many OFT models predict that foraging behavior should vary in allor-none fashion. The Krebs et al. (1978) model is one example, predicting that there should be a sudden switch from sampling to exploitation as a function of experience in the two patches. Many diet selection models predict that under any particular condition, an item either should or should not be included in the diet (e.g., MacArthur and Pianka, 1966). Psychologists have had experience with this issue, since a formerly important controversy was whether animals learned in a gradual, incremental fashion, or in an all-or-none fashion. They found that it can be very difficult to determine whether a particular incremental function found in an experiment is really a step function partially obscured by variability or a true incremental function. 
One complication is that previous experience can affect the shape of learning curves. This is most clearly indicated in the learning set literature. The basic learning set paradigm consists of presenting an animal with a series of many different two-choice discrimination problems. On each discrimination problem, the animal is presented with two stimuli, one arbitrarily designated correct, the other incorrect. The animal is allowed to make several choices, and each choice of the correct stimulus is rewarded with food. After several trials with a problem, a new pair of stimuli, defining a new problem, is introduced, and so on. As learning set training proceeds, the shape of the within-problem learning curve changes quite dramatically. While early problems are solved slowly, in incremental fashion, later problems are solved much more rapidly, and the learning curve begins to resemble a step function (Harlow, 1959). The learning set phenomenon suggests that the extent to which foraging behavior will display the all-or-none functions predicted by OFT may depend upon the previous experience of the animal. For example, the birds tested by Krebs et al. (1978) might have begun to show more sudden shifting from sampling to exploitation with more experience in their perch hop apparatus. In diet selection situations, the extent of partial preferences may depend not only on previous experience with the food types present at the moment, but also on experience with similar dietary choice problems in the past.

\section{Acquisition and transfer experiments}

Another lesson of the learning set literature, as well as other types of animal learning experiments, concerns the problem of determining the "rule of thumb" the foraging animal may use in making its decisions. Most optimal foraging models require fairly sophisticated calculations to mathematically determine the optimal solution to a particular foraging problem. Presumably, the animal does not engage in these calculations, but uses some simpler rule of thumb which approximates the optimal solution (Krebs, 1978). It would be of considerable interest to determine what these rules might be. This question can be translated into asking what stimuli control the behavior of the forager. For example, is the decision to leave a patch based upon the number of prey already found in the patch, the amount of time spent 
there, or the amount of time since the last prey was found (Krebs et al., 1974; Iwasa et al., 1981).

A similar problem arises in the learning set literature. What rule is the experienced animal using to solve new problems so quickly? Many different experiments, conducted primarily with rhesus monkeys and blue jays, indicate that these species use a response strategy known as the "win-stay, lose-shift" strategy (Levine, 1959). The animal remembers what has happened on the previous trial of the current problem and either repeats (stays) or avoids (shifts) that choice, depending on whether it was rewarded (win) or not rewarded (lose).

This research demonstrates that memory for recent events can control behavior in a flexible way, but is of little direct ecological interest. However, the types of experimental designs that have proven useful in identifying the win-stay, lose-shift response rule are relevant. Two of these experimental designs might prove quite useful in research directed at the response rules of foraging animals, studies of acquisition and of transfer.

Acquisition experiments are those which examine the behavior of naive animals as they acquire learning set. For example, the papers by Harlow (1959) and Levine (1959) were particularly influential in demonstrating that even on the first few learning set problems, errors were distributed very systematically, suggesting that the animal was using several response strategies. Since the win-stay, lose-shift strategy is the only one that consistently produces reinforcement, this strategy eventually dominates the behavior of animals with learning set experience. In foraging experiments, this would imply that more attention should be given to how animals behave when initially faced with a foraging problem. Too often, experiments are run by first habituating the animals to the foraging situation until their behavior stabilizes and only then beginning to collect data and vary the independent variable. But behavior during the earlier stages may contain much information about the rules controlling choices during foraging.

In transfer experiments animals are first trained under one set of conditions, then transferred to a different set. Transfer experiments are particularly useful when two or more possible rules of thumb have been identified, but only one will function efficiently under both sets of conditions. If the results of the transfer testing show a high degree of positive transfer, then the rule that applies to both situations is implicated. In the learning set literature, one of the most convincing 
demonstrations of the win-stay, lose-shift rule is the high degree of transfer shown by some species between successive reversal training and learning (Schusterman, 1962; Kamil et al., 1977; successive training consists of using just two stimuli which alternate as the correct stimulus on alternate problems). Since the win-stay, lose-shift rule appears to be the only one that will produce accurate responding, the high degree of transfer strongly implies that this rule is used during both types of problems. In other cases, negative transfer may be found if the two situations involve different rules of thumb (e.g., Behar, 1961).

These acquisition and transfer designs have implications for the field worker as well as the laboratory researcher. For example, young animals that are just beginning their foraging careers probably deserve more detailed attention. Another potential area for research is suggested by transfer designs. Situations in which animals experience sudden change in the characteristics and/or distribution of their prey should be studied.

Finally, it should be noted that acquisition and transfer studies appear throughout the psychological literature, not just in the learning set area (e.g., discussion in Riley, 1969). I have used the learning set literature as a convenient example.

\section{Schedules of reinforcement}

Another area of animal learning research of potential relevance to foraging behavior is schedules of reinforcement. A reinforcement schedule is a rule that determines when reward should be delivered according to the behavior of the animal. For example, if every fourth response is rewarded, then a fixed ratio 4 schedule is in effect. If the first response to occur one minute or more after the last reward occurred is reinforced, then a fixed interval 1 minute schedule is in effect. If the first response to occur 20 or more seconds after the last response is to be rewarded, then a differential reinforcement of low rate 20 second schedule is in effect.

The psychological literature on reinforcement schedules is very large (e.g., Ferster and Skinner, 1957; most issues of The Journal of the Experimental Analysis of Behavior), and many different schedules have been defined. Reinforcement schedules can have an enormous impact on the behavior of animals, influencing both the overall rate and the 
temporal patterning of behavior. From an ecological perspective, the problem with this literature is that the schedules that psychologists have investigated have been selected and defined arbitrarily, with no reference to naturally occurring patterns of reward, such as prey availability. Many of the most commonly studied schedules, particularly the variable interval schedule (Kamil and Yoerg, 1982), appear to be very rare in nature. However, given that schedules are known to have large effects on behavior, the perspective implied by the reinforcement schedule literature could be usefully adapted by ecologists interested in foraging behavior. If the naturally occurring relationships (schedules) between behavior and food were to be detailed empirically, then an integrative body of research could develop. It will be a challenge for the field worker to collect data that will allow the accurate specification of this relationship so that ecologically relevant schedules could be constructed.

One type of schedule of reinforcement with great potential for testing many OFT models is the concurrent schedule. In some reinforcement schedule experiments, only one rewarded response is possible. But in the concurrent situation, the animal can make two or more different responses, each of which can be reinforced on a different schedule. This can be thought of as analogous to having two or more patches in which to hunt, each of which pays off in a different way-at different rates, with different rates of depletion and/or repletion, etc. One of the variables psychologists have studied in concurrent schedules is the effects of a changeover delay, a delay imposed whenever the animal switches from one response alternative to the other (Shull and Pliskoff, 1967). This is exactly analogous to the ecological concept of travel time between patches. These procedures easily could be modified to test many current ideas about foraging behavior, especially in patchy environments.

Although conceptual contributions to foraging can be made by animal learning psychology, the most important contribution may be more methodological. As was implicit in the discussion of schedules of reinforcement many of the apparatuses developed by psychologists could easily be applied to testing of hypotheses about foraging behavior. For example, the one response operant chamber could be used to test the predictions of diet selection models (e.g., MacArthur and Pianka, 1966; Hughes, 1979) by having different stimuli associated with different schedules, simulating prey with different characteristics 
(e.g., Lea, 1979; Collier and Rovee-Collier, 1981). In concurrent schedules with two or more responses available, patch selection models could be tested (e.g., Charnov, 1976). Other traditional psychological apparatuses could also be converted to ecological use, as indicated by the recent development of the radial arm maze (Olton et al., 1981).

Pulliam (1981) has suggested that psychologists may be better able to test many OFT predictions in the laboratory than are ecologists because of the sophistication they have developed in studying conditioning and learning. This is probably true, but an alternative approach would be for behavioral ecologists to learn to use these psychological techniques. This latter strategy may be more fruitful in the long run. In order to understand OFT, a psychologist must first understand the broader ecological framework within which it developed. This would require a considerable shift in general world view for many psychologists. Such changes are very difficult to achieve. But a behavioral ecologist need only learn some new experimental techniques. Learning new methodology is probably much easier than changing basic assumptions and approaches.

It is not impossible for psychologists to adapt an ecological view, and to apply their expertise to testing OFT (e.g., Lea, 1979: Collier and Rovee-Collier, 1981: Olton el al., 1981). Although trained as an experimental psychologist, and originally interested in problems such as conditioning in rats (Kamil, 1969) and learning set formation (Kamil el al., 1977), over the past 7 years my research has focused almost exclusively on problems related to foraging behavior. I have found that much of the training I received as a psychologist and many of the techniques and approaches I learned can be used to good advantage even though my concerns are now primarily ecological. For example, the technique that we have developed in my laboratory for the study of the detection of cryptic prey represents a blend of the psychological and the ecological. In this last section I will describe some of the OFT related research we have carried out recently.

\section{Foraging for Cryptic Prey}

Our technique is based upon procedures developed by R. J. Herrnstein and his colleagues to study "concept formation" in the pigeon (Herrnstein and Loveland, 1964). In these experiments, pigeons are 
shown many different images which are projected, one at a time, onto a pecking key in an operant chamber. Some of these images contain instances of a class of objects, such as people, while the rest do not. If the pigeon pecks at an image that contains an instance of the concept, for example a person, then it is reinforced on a variable interval schedule. If it pecks at an image which does not contain a person, no reinforcement occurs. Both sets of slides are very variable in content. The issue of interest to Herrnstein was whether the pigeons would, in some sense, abstract the concept so that the $\backslash$ would respond appropriately to images the $\backslash$ had never seen before. The pigeons have proven capable of this type of learning.

This procedure, with its use of project images has great potential for a variety of different types of experiments. In our research we have modified the procedures by substituting blue jays for pigeons and cryptic Catocala moths for people in the projected images. We have found that jays will learn to hunt projected images for these moths (Pietrewicz and Kamil, 1977), and have used this procedure to test the search image hypothesis (Pietrewicz and Kamil, 1979, 1981). The technique has two major advantages. Many of the variables which can affect predator choice, such as the appearance, crypticity, and density of the prey, can be precisely controlled. It also allows for very exact measurement of various aspects of the behavior of the jays, such as accuracy and search time. In our more recent research we have turned our attention to some issues suggested by OFT, particularly the marginal value theorem (Charnov, 1976: Fitzpatrick, 1978). In order to test these models, each foraging bout in our simulation was divided into travel, search and handling segments, and giving-up time (GUT) measured. The foraging bout takes place in an operant chamber with two pecking keys, a small round key which the jay can use to start new search intervals and to give up, and a larger rectangular key, called the stimulus key, onto which images can be projected. Each foraging bout consists of many trials. Each trial begins with the illumination of the round key with a white plus sign. This plus sign stays on the key for a certain number of seconds, called the travel time. During the travel time, responses have no effect, although most jays do peck at the round key. At the end of the travel time, a yellow circle is projected onto the round key. The first peck at this yellow circle begins the next phase of the trial, the search phase. During the search phase, an image is projected onto the stimulus key, and a red circle 
is projected onto the round key. The image on the stimulus key may or may not contain a moth, and the bird can end the search phase by pecking at either key.

If the bird pecks at the round key, a giving-up response, both keys are darkened, there is a 2 sec delay to allow the slide projector behind the stimulus key to advance, and the next trial begins with the start of another travel time. If the jay pecks at the stimulus key, an attack response, the round key is darkened and becomes inoperative. A 30 sec approach and handling time then begins, during which the jays usually peck at the stimulus key. At the end of this $30 \mathrm{sec}$ interval, the next peck ends the trial, and, the stimulus key is darkened. If there was a moth in the image, a piece of mealworm is delivered; if no moth was present, no mealworm is delivered. In either case, there is a $2 \mathrm{sec}$ delay to allow the slide projector behind the stimulus key to advance, and then the next trial begins with a new travel time.

In most of our OFT research, all of the images shown on the stimulus key display two or three white birch tree trunks, photographed in the laboratory at a camera-to-subject distance of $1.4 \mathrm{~m}$. The slides are made by setting the camera on a tripod, taking several pictures of a set of tree trunks without prey, then taking several more pictures of the same trunks with prey in different locations on the tree trunks. The prey in these slides are Catocala relicta, a species with white forewings with black disruptive markings, which often rests, and is quite cryptic, upon white birch trees (see Fig. 1). Many slides are made in this way for any experiment, so that the only difference between the slides with moths and those without moths is, on the average, the presence of the moths.

In this simulation, each slide can be considered a patch which may contain one prey or may contain no prey, a reasonable distribution for cryptic prey which usually are highly dispersed. The travel time represents the time that must be spent to reach the patch. Once the jay begins to search the patch it can either decide a moth is present and attack it by pecking at it, or it can decide that no moth is present and give up on the patch and move on to the next patch by pecking at the round key. Our measure of GUT is the latency to peck the round key when no moth is present. According to the marginal value theorem, which Fitzpatrick (1978) has shown can be applied to the zero or one prey per patch case, increases in travel time should produce increases in GUT, a result often obtained in multiple prey per patch situations 


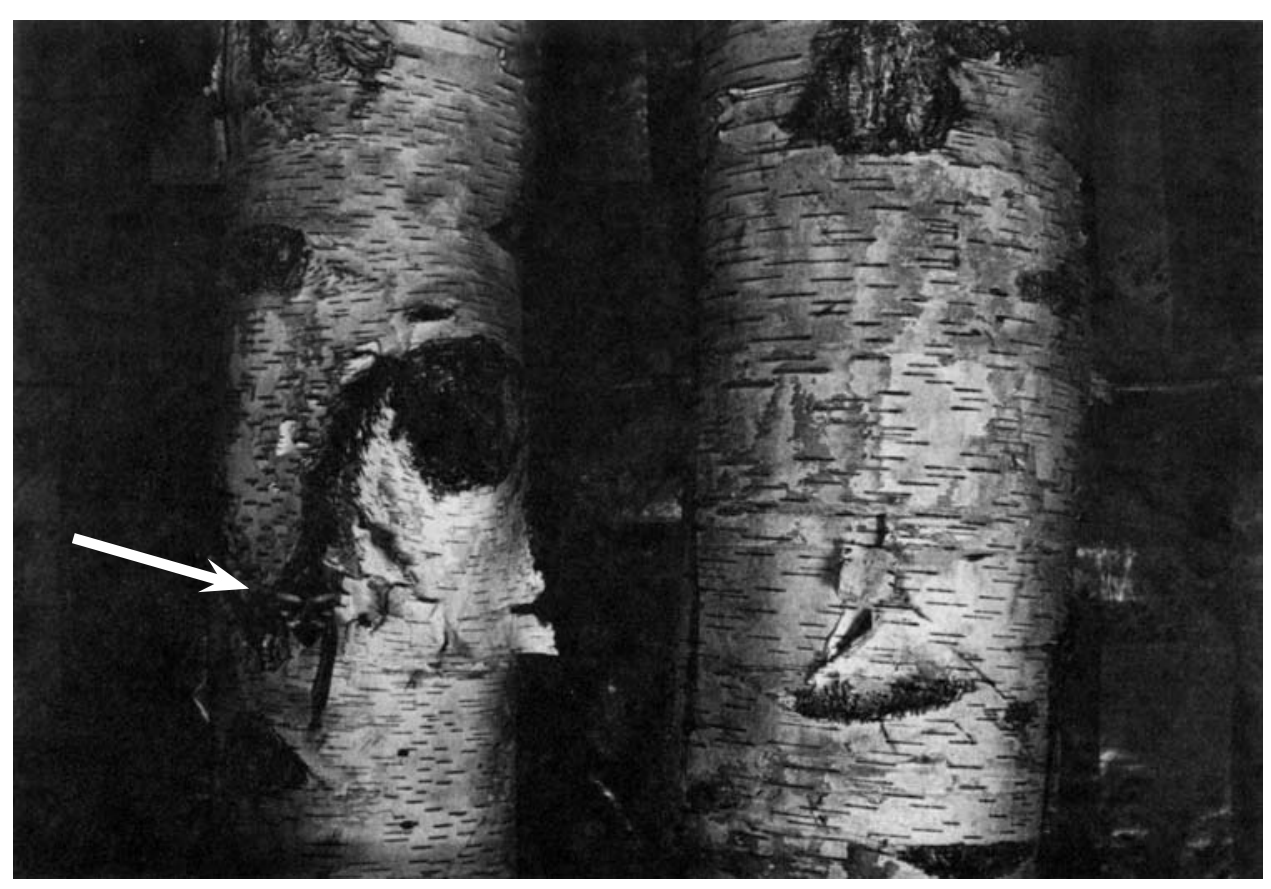

Fig. 1. A Catocala relicta resting on birch. The moth is located in the bottom half of the tree on the left.

(e.g., Cowie, 1977). We tested this prediction in our first experiment (Kamil, Lindstrom, and Peters, in preparation). Five jays were tested at each of three travel times, 5, 15 and $30 \mathrm{sec}$. Each bird received each travel time for 5 consecutive days, and prey density was $269 \mathrm{c}$ throughout the experiment. As predicted, increases in travel time did produce increases in GUT (see Fig. 2).

Although the qualitative results are consistent with the marginal value theorem, more detailed analyses indicate that this model is not appropriate for our data. One indication is shown in Figure 3; accuracy changed systematically as a function of travel time. As travel time increased, the percentage of moths found decreased, while the percentage of correct giving-up responses increased. This result is not predicted by the marginal value theorem and serves as an example of the importance of not limiting data collection to the dependent variables suggested by OFT. Further analysis showed that in most cases, the jays were leaving patches when their expected rate of intake within the patch as a function of time in patch was rising. This, and several other analyses suggested that the jays were not using time in patch exclusively in deciding when to leave. 


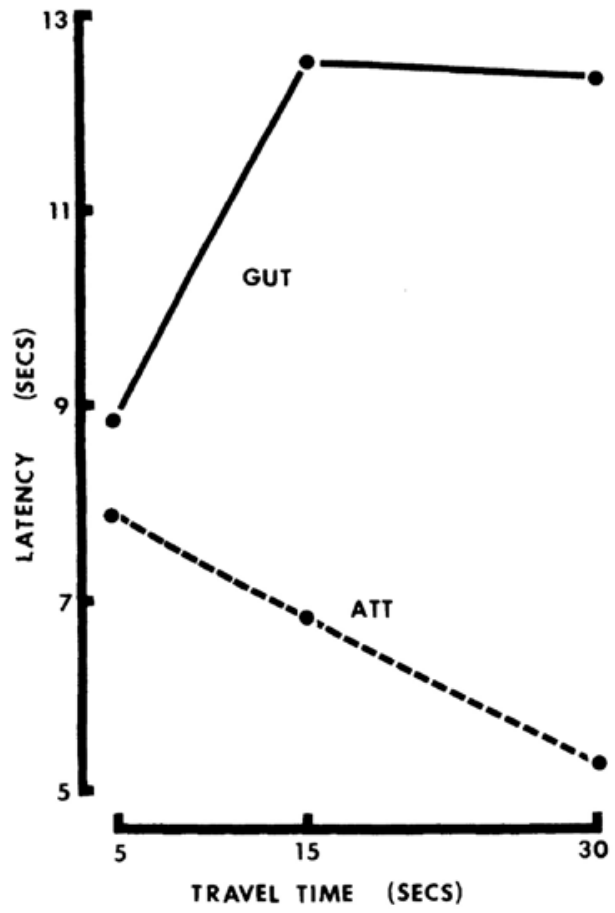

Fig. 2. Mean giving-up times (GUT, latency to reject an image without a moth) and attack times (latency to peck at a moth when present) as a function of travel time.

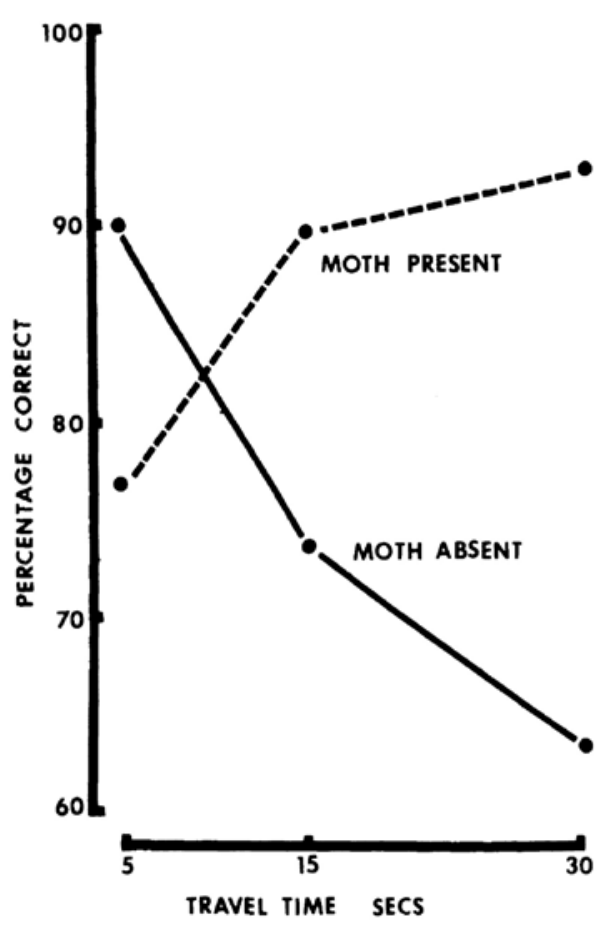

Fig. 3. Mean accuracy of giving-up and attack responses as a function of travel time.

This has stimulated us to begin to carryout additional experiments to determine what factors besides time in patch might affect GUT. Several experiments are in progress. In one experiment Peters and I are finding that the difficulty of the slide affects GUT. When the perceptual difficulty of finding a moth was increased by increasing the camera-to-subject distance GUT increased considerably. In contrast, Olson and I have found that prey density seems to have no effect on GUT. When we presented two types of slides (pictures of oak trees $v s$. pictures of birch trees) which differed in their probability of including a prey item, no effect on GUT was found. We intend to continue this empirical search for variables affecting GUT over the next year, looking at variables such as profitability and handling time in future experiments.

Although the predictions of OFT have not been supported very strongly in this research to date, OFT has served a crucial function. 
By directing our attention to the importance of GUT, it has stimulated us to carry out research which has revealed some interesting phenomena which may prove of quite general importance.

The cryptic prey situation is one that is particularly difficult to study in the field. It is hard to know where the prey are, exactly when the predator detects them, and when giving-up responses occur. This makes cryptic prey detection a particularly appropriate case for laboratory simulation. The results we have obtained with procedures based upon operant conditioning techniques demonstrate the practicality of using psychological techniques to investigate foraging behavior.

Acknowledgments - I thank Deborah Olson and Sonja Yoerg for their comments on an earlier version of this manuscript. Preparation of this manuscript and much of the research described in it were supported by NSF grant BNS 81-02335.

\section{References}

Behar, I. 1961. Analysis of object alternation learning in rhesus monkeys. J. Comp. Physiol. Psych. 54:539-542.

Charnov, E. L. 1976. Optimal foraging: The marginal value theorem. Theor. Pop. Biol. 9:129-136.

Collier, G. H. and C. K. Rovee-Collier. 1981. A comparative analysis of optimal foraging behavior: Laboratory simulations. In A. C. Kamil and T. D. Sargent (eds.), Foraging behavior: Ecological, ethological, and psychological approaches, pp. 39-76. Garland/S.T.P.M., New York.

Cowie, R. J. 1977. Optimal foraging in Great Tits (Parus major). Nature 268:137-139.

Curio, E. 1973. Towards a methodology of teleonomy. Experientia 29:1045-1058.

Ferster, C. B. and B. F. Skinner. 1957. Schedules of reinforcement AppletonCentury-Crofts, New York.

Fitzpatrick, J. W. 1978. Foraging behavior and adaptive radiation in the avian family Tyrannidae. Ph.D. Diss., Princeton University.

Gill, F. B. and L. L. Wolf. 1975. Foraging strategies and energetics of East African sunbirds at mistletoe flowers. Amer. Nat. 109:491-510.

Glander, K. E. 1981. Feeding patterns in mantled howling monkeys. In A. C. Kamil and T. D. Sargent (eds.), Foraging behavior: Ecological, ethological, and psychological approaches, pp. 231-258. Garland Press/S.T.P.M., New York.

Goss-Custard, J. D. 1981. Feeding behavior of redshank, Tringa totanus, and optimal foraging theory. In A. C. Kamil and T. D. Sargent (eds.), Foraging behavior: Ecological, ethological, and psychological approaches, pp. 115-134. Garland Press/S.T.P.M., New York. 
Gould, S. J. and R. C. Lewonton. 1979. The spandrels of San Marco and the Panglossian paradigm: A critique of the adaptionist programme. Proc. Royal Soc. London 205:581-598.

Harlow, H. F. 1959. Learning set and error factor theory. In S. Koch (ed.), Psychology: A study of science, Vol. 2, pp. 492-537. McGraw-Hill, New York.

Heinrich, B. 1983. Do bumblebees forage optimally, and does it matter? Amer. Zool. 23:273-281.

Herrnstein, R. J. and D. H. Loveland. 1964. Complex visual concept in the pigeon. Science 146: 549-551.

Hodos, W. and C. B.C. Campbell. 1969. Scala naturae: Why there is not theory in comparative psychology. Psych. Rev. 76:337-350.

Hughes, R. N. 1979. Optimal diets under the energy optimization premise: The effects of recognition lime and learning. Amer. Nat. 1 13:209-221.

Iwasa, Y., M. Higashi, and N. Yamamura. 1981. Prey distribution as a factor determining the choice of optimal foraging strategy. Amer. Nat. 1 17:710-723.

Kamil, A. C. 1969. Some parameters of the second-order conditioning of fear J. Comp. Physiol. Psych. 67:364-369.

Kamil, A. C, T. B. Jones, A. T. Pietrewicz, and J. Mauldin. 1977. Positive transfer from successive reversal training to learning set in blue jays. J. Comp. Physiol. Psych. 91:79-86.

Kamil, A. C. and S. I. Yoerg. 1982. Learning and foraging behavior. In P. P. G. Bateson and P. H. Klopfer (eds.), Perspectives on ethology, Vol. 5. Plenum, New York. (In press)

Krebs, J. R. 1978. Optimal foraging: Decision rules for predators. In J. R. Krebs and N. B. Davies (eds.), Behavioural ecology: An evolutionary approach, pp. 23-63. Blackwell, Oxford, England.

Krebs, J. R. and N. B. Davies. 1981. Introduction to behavioural ecology. Blackwell, Oxford, England.

Krebs, J. R., A. Kacelnik, and P. Taylor. 1978. Test of optimal sampling by foraging great tits. Nature 275:27-31.

Krebs, J. R., J. C. Ryan, and E. L. Charnov. 1974. Hunting by expectation or optimal foraging? A study of patch use by chickadees. Animal Behav. 22:953-964.

Lea, S. E. G. 1979. Foraging and reinforcement schedules in the pigeon: Optimal and non-optimal aspects of choice. Animal Behav. 27:821-828.

Levine, M. 1959. A model of hypothesis behavior in discrimination learning set. Psych. Rev. 66: 353-366.

Lockard, R. B. 1971. Reflections on the fall of comparative psychology: Is there a message for us all? Amer. Psychologist 26:168-179.

MacArthur, R. H. and E. R. Pianka. 1966. On optimal use of a patchy environment. Amer. Nat. 100:603-609.

Maynard-Smith, J. 1978. Optimization theory in evolution. Ann. Rev. Ecol. System. 9:31-56.

Olton, D. S., G. E. Handelman, and J. A. Walker. 1981. Spatial memory and food searching strategies. In A. C. Kamil and T. D. Sargent (eds.), Foraging behavior: 
Ecological, ethological, and psychological approaches, pp. 333-354. Garland Press/S.T.P M., New York.

Orians, G. H. 1981. Foraging behavior and the evolution of discriminatory abilities. In A. C. Kamil and T. D. Sargent (eds.), Foraging behavior: Ecological, ethological and psychological approaches, pp. 389-406. Garland/S.T.P.M., New York.

Pietrewicz, A. T. and A. C. Kamil. 1977. Visual detection of cryptic prey by blue jays (Cyanocitta cristata). Science 195:580-582.

Pietrewicz, A. T. and A. C. Kamil. 1979. Search image formation in the blue jay (Cyanocitta cristata). Science 204:1332-1333.

Pietrewicz, A. T. and A. C. Kamil. 1981. Search images and the detection of cryptic prey: An operant approach. In A. C. Kamil and T. D. Sargent (eds.), Foraging behavior: Ecological, ethological, and psychological approaches, pp. 311-332. Garland/S.T.P.M., New York.

Pulham, H. R. 1980. Learning to forage optimally. In A. C. Kamil and T. D. Sargent (eds.), Foraging behavior: Ecological, ethological, and psychological approaches, pp. 379-388. Garland/S.T.P.M., New York.

Riley, D. A. 1968. Discrimination learning. Allyn and Bacon, Boston.

Schusterman, R.J. 1962. Transfer effects of successive discrimination-reversal training in chimpanzees. Science 137:422-423.

Seligman, M. E. P. 1970. On the generality of the laws of learning. Psych. Rev. 77:406-418.

Shull, R. L. and S. S. Pliskoff. 1967. Changeover delay and concurrent schedules: Some effects on relative performance measures. J. Exp. Anal. Behav. 10:517-527.

Smith, J. N. M. and H. P. A. Sweatman. 1974. Food searching behavior of titmice in patchy environments. Ecology 55:1216-1232.

Tinbergen, L. 1960. The natural control of insects in pine woods. I. Factors influencing the intensity of predation in song birds. Arch. Neerlandaise Zool. 13:265-343.

Tinbergen, N. 1963. On aims and methods of ethology. Zeitschrift für Tierpsychologie 20:410-429.

Uhl, C. N. 1963. Two-choice probability learning in the rat as a function of incentive, probability of reinforcement, and training procedure. J. Exp. Psychol. 66:443-449.

van Lawick-Goddall, J. 1968. The behavior of free-living chimpanzees in the Gambe Stream Reserve. Animal Behav. Monographs 1:161-311.

Vehrencamp, S. L. 1977. Relative fecundity and parental effort in communally nesting Anis, Crotophaga sulcirostris. Science 197:403-405.

Zach, R. and J. N. M. Smith. 1980. Optimal foraging in wild birds? In A. C. Kamil and T. D. Sargent (eds.), Foraging behavior: Ecological, ethological, and psychological approaches, pp. 95-110. Garland/S.T.P.M., New York. 